\title{
A ANÁLISE DO DISCURSO DE LINHA FRANCESA E SUAS INTERFACES
}

\author{
Bianca Cavichia Desidério*
}

\begin{abstract}
RESUMO: O presente artigo tem por proposta realizar uma reflexão teórica acerca das bases epistemológicas sobre as quais fundou-se a Análise do Discurso de linha francesa (AD), como concebida pelo francês Michel Pêcheux ainda na década de 1960. É interesse especial da discussão que aqui se coloca delinear, cronologicamente, um panorama que elucide o ponto em que o Materialismo Histórico, a Psicanálise e a Linguística se encontram para fundar os conceitos-chave do quadro teórico da AD. Com base, portanto, em um trabalho de revisão bibliográfica, pretende-se compreender a afirmação de Eni Orlandi, qual seja, que "a AD se configura como um disciplina de entremeio”. Para tal, pensar-se-á no papel que determinados conceitos - como ideologia (segundo Althusser) e inconsciente (segundo Lacan) - desempenharam no processo de reformulação da noção estruturalista de língua, vigente na década de 1960, e, consequentemente, para o estabelecimento do conceito pêcheuxtiano de discurso.
\end{abstract}

ABSTRACT: This paper intends to develop a theoretical discussion on the epistemological bases on which the French Discourse Analysis, as conceived by Michel Pêcheux during de 1960's, was founded. This discussion has a special interest in outlining, chronologically, an overview that enlightens the point in which the Historical Materialism, the Psychoanalysis and the Linguistics find each other to establish the key concepts of the French Discourse Analysis. Therefore, it is the intention of this discussion to comprehend, based on a bibliographic search, Eni Orlandi's statement, that is "The Discourse Analysis is an in between theory". In order to understand this statement, an analysis about concepts such as ideology (as according to Althusser) and unconscious (according to Lacan) will be carried out. These concepts were fundamental to the process of reformulating the structuralist notion of language that was in effect during the 1960's, and, therefore, the stablishing of Pêcheux's notion of discourse.

PALAVRAS-CHAVE: 1) Análise do Discurso de linha Francesa; 2) Teoria das Ideologias; 3) Michel Pêcheux.

KEYWORDS: 1) French Discourse Analysis; 2) Ideologies Theory; 3) Michel Pêcheux.

\section{INTRODUÇÃO}

Concebida por um grupo de filósofos, linguistas, psicanalistas e historiadores na década de 1960, a Análise do Discurso (AD) surge de modo a tecer reflexões que causaram uma ruptura com o "narcisismo universal do pensamento humano", no interior do qual o sujeito era considerado um estrategista consciente, racional e lógico-operatório, limitado tanto por determinações biológicas como por determinações sociológicas (FERREIRA, 2011, p. 243). No contexto intelectual filosófico e político da década de 1960 via-se, assim, um movimento de tentativa de construção de um universo logicamente estável, como Ferreira (Ibid.) explicita em trecho retirado de livro articulado em homenagem à Eni Orlandi: 
Na construção desse universo logicamente estabilizado, em que se situava o contexto político e filosófico da época, a história entrava como resultante de uma série de situações de interações reais ou simbólicas. E trazia consigo uma marca teleológica, progressista, evolucionista. Apagava-se dela, portanto, qualquer vestígio de conflito incontornável, de contradição. Da língua, o que se esperava era que refletisse uma parte dessas interações simbólicas, o que só se tornava possível por sua natureza transparente e estável. Já o inconsciente era considerado, ainda nas palavras de Pêcheux, como a não consciência que se manifestava negativamente em algum setor da atividade do sujeito, em decorrência das tais determinações biológicas e/ou sociais [...]”".

As concepções, vigentes nas décadas de 1950 e 1960, de língua, de história e de inconsciente (ou, melhor, a não consideração da questão do inconsciente) determinavam o modo como o sujeito era compreendido no interior de tal quadro intelectual filosófico. Aliás, no auge do estruturalismo, que marcava a época em questão na França, o sujeito era constantemente excluído dos debates intelectuais pelos defensores da fenomenologia, do psicologismo e da hermenêutica - que constituíam o paradigma estrutural que delineava o panorama filosófico da França até 1967 (época do apogeu do estruturalismo). Essa exclusão deliberada do sujeito explica-se pela própria concepção que se tinha de língua, uma vez que trazer a questão do sujeito significava trazer um elemento suscetível de perturbar a análise da língua objetivada, padronizada, homogênea e transparente que se constituía enquanto objeto científico dos estruturalistas.

No interior de um excessivo formalismo que buscava automatizar a relação com a linguagem, o sujeito, a língua e a historicidade estavam às margens das discussões teóricas e filosóficas. No interior desse panorama, o sujeito era tomado como centrado em seu próprio eixo, senhor de seus atos, livre do funcionamento do inconsciente, do equívoco e da contradição. A AD francesa entende o sujeito como sendo afetado simultaneamente por ordens distintas, nas quais ele deixará um furo: "o furo da linguagem, representado pelo equívoco; o furo da ideologia, expresso pela contradição, e o furo do próprio sujeito, manifesto pelo inconsciente" (FERREIRA, 2011, p. 344). Falamos aqui de uma tríade fundamental para o quadro teórico do discurso, da qual decorre a incompletude que o caracteriza tão fortemente: a tríade real da língua - real da história - real do sujeito.

A Análise do Discurso - na figura de seu principal articulador, o intelectual francês, Michel Pêcheux - posicionou-se politicamente frente às teorias vigentes, trazendo um dispositivo teórico-metodológico de interpretação de discursos políticos; dispositivo esse que, baseado nos estudos marxistas e mantendo relação com os estudos da linguagem, compreendia a língua como opaca e a historicidade e o político como sendo constitutivos da produção de efeitos de sentido. Em meio ao conturbado contexto político e filosófico que caracterizava a França dos anos 60, a Análise do Discurso proposta por Michel Pêcheux erigiu-se, assim, no entremeio da Linguística, do Materialismo Histórico e da Psicanálise. 
A relação estabelecida por Michel Pêcheux com a Linguística foi de cunho crítico. Uma relação que tinha por intuito não concordar ou discordar, mas operar um deslocamento sensível no interior da própria área, especialmente sobre os conceitos de língua, historicidade e sujeito, de modo a possibilitar uma espécie de combate ao excessivo formalismo linguístico então vigente. A AD de linha francesa estende à linguagem um papel fundacional (FERREIRA, 2010, p. 18) na constituição de sujeitos e de sentidos. Segundo Ferreira (2010):

Fica claro, desse modo, que a $\mathrm{AD}$ não se vê como uma disciplina autônoma, nem tampouco como disciplina auxiliar. O que ela visa é tematizar o objeto discursivo como sendo um objeto-fronteira, que trabalha nos limites das grandes divisões disciplinares, sendo constituído de uma materialidade linguística e de uma materialidade histórica, simultaneamente (p. 18).

Mais do que uma teoria interdisciplinar, a $\mathrm{AD}$ vai se configurar como o que Orlandi chama de disciplina de entremeio, uma vez que ela está no entremeio das tendências formalista (gerativismo), sociologista (sócio, etnolinguística) e da fala (teorias da enunciação, análise conversacional). Dizemos que a AD é uma disciplina de entremeio não por ser considerada a quarta dessas tendências, mas porque "se constitui no lugar produzido pela relação contraditória entre as três existentes" (ORLANDI, 2012, p. 24). Orlandi explica que a AD não é interdisciplinar já que não se formou entre disciplinas, mas nas suas contradições. É preciso ter claro, assim, o fato de que a AD não é somente a "aplicação" da Linguística sobre as ciências sociais, e vice-versa; pensar dessa forma seria desconsiderar suas especificidades, as quais produzem um novo lugar de conhecimento ocupado por essa teoria de interpretação de discursos. É sobre o processo de construção de tal lugar que versaremos a seguir.

\section{OS ESPAÇOS RELACIONAIS ESTABELECIDOS PELA ANÁLISE DO DISCURSO: A LINGUÍSTICA, O MATERIALISMO HISTÓRICO E A PSICANÁLISE}

Seria estranho que os analistas do discurso fossem os últimos a saber da conjunção existente entre a cegueira quanto à história e a surdez quanto à língua que diz respeito a seus objetos e a suas práticas (Michel Pêcheux, em O Estranho Espelho da Análise do Discurso, p. 26).

A Análise do Discurso que se convencionou denominar de $A D$ de linha francesa teve no intelectual francês, Michel Pêcheux, seu principal articulador. Mobilizando conceitos originários da teoria marxista e da psicanálise freudiana, respectivamente nas releituras de Louis Althusser e Jacques Lacan, Pêcheux provocou um deslocamento (um re-traçado de limites) no conceito saussuriano de língua, formulando então um novo objeto: o discurso. 
Discutiremos neste tópico aspectos da relação da Análise do Discurso com a linguística, com o materialismo histórico e com a psicanálise, atentando aos movimentos teóricos em relação a cada uma dessas disciplinas, os quais levaram Michel Pêcheux a elaborar as noções-chave do dispositivo teórico e metodológico da AD.

Segundo Orlandi (2002),

[...] a AD mantém o estudo linguístico como espaço aberto de questões sobre o próprio da língua, não procurando fechá-lo seja porque se exclui da ordem do significante o que não é gramática, seja porque, ao contrário, se visa um objeto total, numa forma que integre tudo iludindo-se com o desconhecimento da presença da contradição na ciência.

Ao ligar a língua (enquanto sistema fechado) e a exterioridade, a língua e a ideologia e a língua e o inconsciente, a AD de Pêcheux des-territorializou (ORLANDI, 1999, p. 22) terrenos teóricos até então bem firmados na França e marcados por uma prática positivista nas ciências humanas e sociais.

Dos espaços relacionais estabelecidos entre a $\mathrm{AD}$ e outras disciplinas, o mais desenvolvido por Michel Pêcheux foi aquele com a Linguística, o que se explica pela própria conjuntura científica da época, no interior da qual ela desempenhava o papel de ciência-piloto entre as ciências humanas, tendo na figura do pensador Ferdinand de Saussure seu "pai". No entanto, Pêcheux ao mesmo tempo que reivindicava o legado de Ferdinand de Saussure também advogava a necessidade de ultrapassá-lo. Advogava sobretudo a necessidade de focalizar questões que não haviam sido muito focadas nas reflexões que se desenvolveriam no campo de estudos da linguagem a partir de Saussure, como as do sujeito e da história. Falamos aqui, especificamente, da subjetividade na linguagem e da ordem do discurso.

\begin{abstract}
A linguística saussuriana é mobilizada, em Michel Pêcheux, por um duplo motivo: primeiro, pela autonomia relativa da linguagem, unanimemente reconhecida pelas Ciências Humanas, na conjuntura estruturalista. E, segundo, no concerto das Ciências Humanas, a linguística era reconhecida por ter operado de maneira decisiva o corte epistemológico, isto é, o distanciamento necessário da sua própria ideologia que qualifica a cientificidade (SARGENTINI; BARONAS, 2007, p. 47).
\end{abstract}

A partir da interface que estabeleceu com a Linguística, Pêcheux desenvolveu uma releitura da noção de língua, a qual passou a ser tomada, como propõe Orlandi, em sua forma material, isto é, como um sistema sintático sujeito à falha, ao equívoco. Ela deixa, então, de ser concebida enquanto código ideologicamente neutro e passa a ser trabalhada enquanto um sistema relativamente autônomo passível de perturbações e falhas, enquanto lugar material de realização dos processos discursivos, onde se constituem os sentidos. A língua da $\mathrm{AD}$, diferente, portanto, daquela da Linguística, tem um funcionamento afetado pela ideologia. 
E como a Análise do Discurso re-significa a língua enquanto objeto de reflexão?

Ela o fez ao deslocar a dicotomia saussuriana língua e fala para a relação não-dicotômica língua e discurso. Pêcheux concordava com Ferdinand de Saussure no que diz respeito à língua ser um fato social, mas via a necessidade de refletir sobre como o social é significado, então, nela. O meio de fazê-lo - e aqui está uma das singularidades da AD foi "ligar a língua e a exterioridade, a língua e a ideologia, a ideologia e o inconsciente" (ORLANDI, 2002, p. 22).

Esse movimento de re-significação da língua possibilitou a reintrodução do sujeito e da situação no campo dos estudos da linguagem, os quais também passaram por um processo teórico de redefinição. O que ocorreu foi que a Linguística que se constituiu a partir de Saussure, ao fundamentar-se numa dicotomização da relação língua e fala, tomou a língua como objeto total, sendo considerada uma teoria que daria conta, por si só, de todas as questões relacionadas a ela (língua); isso "autorizou o reaparecimento triunfal do sujeito falante como "subjetividade em ato"' (ORLANDI, 2002, p. 23), isto é, do sujeito senhor de suas intenções, as quais realizar-se-iam por meio de instrumentos linguísticos colocados à sua disposição.

Ao deslocar a dicotomia saussuriana língua (social, geral, sistemática) e fala (individual, assistemática, singular) para a relação, que não se dicotomiza, língua e discurso, a AD produziu um espaço teórico que, ao contrário do movimento estruturalista, reconhecia a intrínseca relação entre a exterioridade (o social, o histórico, o casual) e o linguístico. Colocar a noção de discurso - e não mais a de fala - em relação com a re-significada noção de língua possibilitou à $\mathrm{AD}$, então, pensar o texto em termos de funcionamento.

Aqui, entramos naquilo a que se refere Eni Orlandi (2002, p.23) quando fala em forma material da língua:

E é a isso que, em meus trabalhos, refiro como forma material, linguísticohistórica, fazendo intervir a noção de interdiscurso (que refiro como memória, saber discursivo): alguma coisa fala antes, em outro lugar e independentemente (M. Pêcheux, 1975). Não se abandona o exterior específico mas ele é atravessado pelo exterior constitutivo (o interdiscurso).

A noção de forma-material coloca em jogo a importância da relação entre língua e história dentro do quadro epistemológico da $\mathrm{AD}$; relação desenvolvida sobretudo a partir da (re)leitura que Michel Pêcheux fez de conceitos advindos do materialismo histórico. Através da noção de forma-material a AD trabalha a inscrição do histórico na língua, o que coloca em questão a própria ordem do discurso, afinal, como afirma Orlandi (1999), "a ordem da língua e a da história, em sua articulação e funcionamento, constituem a ordem do discurso". 
O materialismo histórico tem papel decisivo para a articulação de uma teoria do discurso, tendo contribuído com conceitos que se configuram como centrais no arcabouço teórico da $\mathrm{AD}$, como o próprio conceito de história:

[...] a noção de história é daquelas noções fundadoras que constituem o território discursivo. Afinal, a história intervém na língua e no processo de constituição dos sentidos. Nessa perspectiva, a exterioridade não tem a objetividade empírica daquilo que está fora da linguagem, já que ela é constitutiva do próprio trabalho dos sentidos atuando em determinados textos, enquanto discursos (FERREIRA, 2010, p. 19).

$\mathrm{O}$ que Ferreira nos elucida no trecho acima transcrito é que, para a $\mathrm{AD}$, a inscrição da história se dá no interior dos discursos e não mais na exterioridade linguística. Esse deslocamento se deu por consequência das reflexões de Pêcheux, quem trabalhou a intervenção da história na língua e no processo de constituição dos sentidos de modo a considerá-la o lugar contraditório em que se materializam os equívocos, e não enquanto puro efeito imaginário. Segundo o francês, o equívoco afeta a univocidade linguística do sujeito, levando-o ao encontro do real histórico; ele (o equívoco) "aparece exatamente como o ponto em que o impossível (linguístico) vem aliar-se à contradição (histórica); o ponto em que a língua atinge a história" (PÊCHEUX, 2004, p. 64, destaque nosso).

\footnotetext{
No domínio discursivo, interessam tanto as falhas na ordem da língua quanto o modo específico de construção de uma linearidade 'narrativa'. Ou melhor, é a análise da(s) posição(ões) discursiva(s) inscrita(s) em uma produção textual qualquer, com sua ordem, organização e falhas peculiares que interessa(m) ao analista do discurso. O que o sujeito diz, seja lá como for, diz dentro da história. O que falha na prática discursiva do sujeito, o que derrapa nessa prática, também é algo que se dá dentro da história. E é por isso que produz sentido. As falhas na ordem significante se realizam em condições de produção determinadas, são o resultado do funcionamento da língua em relação ao inconsciente e à ideologia (MARIANI, 2003, p. 65).
}

Para a perspectiva discursiva, o conceito de ideologia encontra-se entre a língua e a história, aparecendo como "efeito da relação necessária do sujeito com a língua e com a história, para significar" (ORLANDI, 1996, p. 28).

Para entender a força que o conceito de ideologia tem para o quadro epistemológico proposto por Michel Pêcheux é preciso entender a força de sua filiação althusseriana. Foi, afinal, através de seu movimento de releitura de Marx através da obra de Louis Althusser que Pêcheux estabeleceu a centralidade que o conceito de ideologia assumiria em sua teoria do discurso, em sua reflexão sobre o sujeito. No entanto, mais do que simplesmente remeter o trabalho de Pêcheux ao de Althusser, é preciso entender, como bem o coloca, Barbosa Filho (2012, p. 39) "o que Pêcheux fez do que leu". 


\section{O QUE O MATERIALISMO UNE, A LINGUAGEM "SEPARA": TEORIA DAS IDEOLOGIAS}

Materialista rigoroso, Louis Althusser considerava que o sujeito é o sujeito da ideologia. A tese central de Louis Althusser é de que a ideologia interpela os indivíduos em sujeitos, isto é, a ideologia e a própria possibilidade de ser sujeito são, para ele, uma só e mesma coisa. Althusser não estava diretamente interessado na linguagem, mas reconhecia o papel central dela na constituição subjetiva, fato que se explicitava em seu postulado sobre "as duas evidências fundamentais nesse processo, a saber, a evidência do sujeito e a transparência da linguagem" (RODRÍGUEZ, 2000, p. 16). A percepção de que havia na linguagem questões importantes a serem trabalhadas para compreender problemáticas marxistas relativas ao sujeito e à história fica nítida pelas próprias aproximações que Althusser estabeleceu com Freud, através da leitura que Lacan fez deste autor. Foi Pêcheux, no entanto, que buscou trazer, de fato, a empresa althusseriana para o interior do trabalho com a linguagem. É justamente a tal fato que Barbosa Filho (2012, p. 39) se refere quando afirma que "o que une Louis Althusser a Michel Pêcheux é o materialismo, o que os "separa" (no sentido de direcionar) é a linguagem". Trazendo as colocações que Althusser tinha proposto para fora do campo de investigação althusseriano, Pêcheux foi à linguagem procurar uma das instâncias nas quais se materializa a ideologia.

O texto Observações para uma teoria geral das ideologias (1967), assinado sob o pseudônimo Thomas Herbert, é um exemplo de texto em que Pêcheux formula questões as quais ele procuraria responder ao longo de toda a sua obra, entre elas a questão da ideologia. Marcado pelo "jargão do discurso político da época", esse texto mostra-se um "um registro muito elucidativo desse momento primeiro na constituição de uma disciplina, que o próprio Pêcheux chama de 'trabalho teórico-conceptual', no qual ela 'se dá a palavra' e efetua a 'transformação produtora' de seu objeto" (RODRÍGUEZALCALÁ, 2005, p. 16). Nele vemos o pensador francês refletir sobre uma teoria das ideologias de modo a já lançar as bases da relação entre ideologia, inconsciente e sujeito, intervindo nessa relação, como já o apontamos, através da introdução do objeto de sua teoria, ou seja, o discurso.

O texto de 1967, anterior à fundação da AD, tem importância histórica, pois nele Pêcheux já esboçava algumas noções que posteriormente foram desenvolvidas de modo a compor o quadro teórico da Análise do Discurso, e as quais estavam todas ligadas à noção de ideologia: formações ideológicas, posição-sujeito, esquecimentos, metáfora, metonímia, efeitos, discurso. Ao pensar, portanto, a questão da ideologia do ponto de vista do funcionamento da linguagem, no campo do discurso, Pêcheux elaborou o aparato teóricoanalítico da AD.

O autor opõe-se, nesse texto, a uma interpretação economicista dos mecanismos ideológicos, já que, para ele, a simplificação de uma posição econômico-determinista não 
permitiria compreender as contradições no sistema. Outro importante ponto que Pêcheux traz em seu texto de 1967 foi a diferenciação entre duas formas predominantes de funcionamento da ideologia, que funcionam segundo esquecimentos específicos e ilusões: a ideologia empírica e a ideologia especulativa.

A forma empírica da ideologia diz respeito à relação entre uma "significação" e a "realidade que lhe corresponde", entre "significante" e "significado". Rodríguez-Alcalá (2005, p. 17) explica que, para o autor, nesse "eixo semântico (vertical)", a relação entre as palavras e as coisas é tomada como uma relação natural, direta, e a língua como o "código" que permite nomeá-la. A partir dessa forma da ideologia, o homem ocupa o lugar de produtor-distribuidor de significações na superfície da "realidade". Há aqui a pressuposição de uma passagem contínua e homogênea entre a ordem natural e a ordem humana, fato que desconsidera a especificidade simbólica do "animal humano". Pêcheux defende que não há gênese do significante, o que, por sua vez, se contrapõe à ideia de produção-distribuição de significantes.

Já a forma especulativa da ideologia, ou "eixo sintático (horizontal)", articula significantes entre si, sob a forma geral do discurso. Neste caso, o homem torna-se o animal social, "o animal dotado de linguagem que se controla a si mesmo graças à linguagem". Ainda em sua discussão a respeito do texto de Herbert/Pêcheux, RodríguezAlcalá (2005) ressalta que, para esse autor, as relações entre sujeitos são entendidas como relações "naturais", cuja natureza seria precisamente a natureza linguística do "animal humano", como "animal social apto para intercambiar significações codificadas". A questão central colocada por Pêcheux neste caso é a da diferença entre as relações naturais e as relações sociais. Segundo ele, as relações sociais não são relações que outrora foram naturais e depois deixaram de sê-lo. Pensar o funcionamento da sociedade em termos "naturais", isto é, pensá-la como um mero sistema em funcionamento, cujos membros se comunicam com a ajuda de códigos, representa, segundo Pêcheux, um recalque da instância política.

Ao reconhecer o papel do simbólico e do político no funcionamento da ideologia, Pêcheux procurou evitar desenvolvimentos mecanicistas do conceito marxista de ideologia (ideologia como "falsa consciência", como "alienação").

O texto de Pêcheux institui-se diretamente contra o domínio do paradigma (neo) positivista nas ciências, que de acordo com Rodríguez-Alcalá pode ser caracterizado pela consideração da vida humana como sendo um fenômeno natural. A teoria geral das ideologias proposta por Pêcheux tinha justamente o objetivo de desconstruir essa ideia por meio do reconhecimento de que a vida humana não é o reflexo da natureza, mas o resultado de um trabalho (simbólico, político) sobre ela. Não haveria, nessa perspectiva antipositivista, uma passagem direta entre a ordem natural e a ordem humana, mas um corte simbólico realizado em e através de mecanismos linguísticos (discursivos). 
Considerando o exposto, emprestamos agora o quadro proposto por Carolina RodríguezAlcalá (2005) para melhor visualizarmos o funcionamento da dupla forma da ideologia:

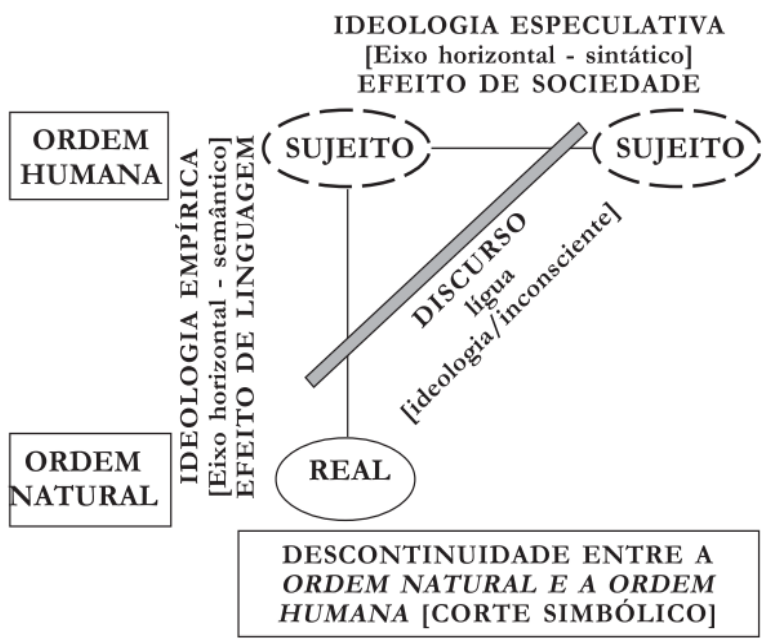

Figura 1 - Esquema proposto por Carolina Rodríguez-Alcalá, 2005, p. 20.

Como se pode observar pela figura acima, é a intervenção da materialidade específica do discurso (a língua), considerada em seu duplo atravessamento pela ideologia e pelo inconsciente, que faz com que a passagem da ordem natural para a ordem humana não seja mais tomada como direta, transparente, como homogênea. A consequência de tal deslocamento (ou seja, para uma noção discursiva de ideologia) é a introdução da falha, do equívoco, do esquecimento e da contradição como elementos estruturantes do político.

Considerando os posteriores desenvolvimentos da obra de Michel Pêcheux - sobretudo os caminhos tomados pela teoria pêcheutiana no Brasil a partir dos trabalhos de Eni Orlandi - vemos que a ideologia é entendida na $\mathrm{AD}$ como "relação política que se constitui na/pela linguagem, num processo que excede a consciência do sujeito" (RODRÍGUEZ, 2000, p. 182). Isso significa que a AD considera que a relação entre o sujeito e o mundo ao qual ele faz referência através da língua não é direta, mas mediada pelo trabalho simbólico/político, o qual é duplamente descentrado pela ideologia e pelo inconsciente. $\mathrm{O}$ sujeito não está ligado diretamente às coisas; as palavras também não estão. O que torna possível essa relação (entre sujeito/palavras e as "coisas") é justamente o funcionamento da ideologia, a qual, para Pêcheux, tem um funcionamento inconsciente. 
Carolina Rodríguez (2000, p. 182) explica que é nesse ponto que o conceito de discurso intervém. O discurso intervém

[...] como essa rede de sentidos construídos na/através da língua, pela qual o sujeito se constitui e se relaciona com o mundo, através da qual a vida social se torna possível. Pensar a ideologia a partir da linguagem, discursivamente, enquanto rede de sentidos, portanto, é considerar que para compreender o sentido das palavras é necessário pô-las em relação com outras.

Como se pode notar, a questão do inconsciente é fundamental no interior da teoria discursiva formulada por Michel Pêcheux, quem, apesar de apresentar em toda sua obra um fascínio pela Psicanálise, em nenhum momento a superpôs ou fez coincidir com o campo teórico do Discurso.

A reflexão acerca da noção freudiana de inconsciente (na releitura lacaniana) aparece com frequência em Semântica e Discurso (1975), obra na qual as referências à teoria de Jacques Lacan são bem frequentes. Nela, Pêcheux busca desenvolver uma analogia entre os conceitos de ideologia e de inconsciente. Para o autor, entre as noções de ideologia e inconsciente "há um modo de constituição mútua que as mantém paradoxalmente interligadas, ainda que sejam distintas (está aí o paradoxo!)” (FERREIRA, 2005, p. 72).

Mais tarde, em seu texto de 1978, Só há causa daquilo que falha ou o inverno político francês: início de uma retificação, Pêcheux faz um exercício de reflexão e autocrítica e se retifica, deixando claro que a ordem do inconsciente não coincide com a da ideologia:

A ordem do inconsciente não coincide com a da ideologia, o recalque não se identifica nem com o assujeitamento nem com a repressão, mas isso não significa que a ideologia deva ser pensada sem referência ao registro inconsciente (PÊCHEUX, 2009, p. 278).

A noção de ideologia trouxe assim para o campo epistemológico da Análise do Discurso uma valiosa contribuição: uma outra concepção de sujeito, a de "um sujeito clivado, assujeitado, submetido tanto ao seu próprio inconsciente quanto às circunstâncias histórico-sociais que o moldam" (FERREIRA, 2005, p. 71).

\section{CONSIDERAÇÕES FINAIS: A MORADA DO SUJEITO DA AD}

Não dá para entrar nessa morada do sujeito sem ser pela porta da linguagem (FERREIRA, 2005, p. 70).

Quando afirma que "a porta para a morada do sujeito" é a linguagem, Ferreira explicita o fato de que para os domínios da Psicanálise e do discurso o sujeito não é dado, 
nem tampouco nasce ou se desenvolve mas é construído. E para compreender o modo pelo qual o sujeito se constrói "é preciso trazê-lo para o campo do qual ele é efeito, isto é, o campo da linguagem” (FERREIRA, 2005, p. 70).

Como o discutido neste artigo, uma questão fundamental na concepção de sujeito da AD é sua definição como resultado de um processo sócio histórico e não como reflexo (psicológico) de características naturais (biológicas). Considerando isso, compreender de que modo a linguagem intervém nesse processo (o qual resulta no sujeito discursivo) torna-se uma tarefa central no interior da perspectiva teórica da AD.

Compreender como a língua acontece no homem, ou, em outras palavras, como o sujeito se constitui como efeito de linguagem, implica uma necessária entrada na questão da subjetividade, a qual coloca em jogo conceitos como os de formação discursiva, formação ideológica, assujeitamento, forma-sujeito. Tais conceitos se conectam entre si na consideração do sujeito discursivo, formando, assim, a tessitura da noção de subjetividade a partir da qual a $\mathrm{AD}$ opera.

A noção discursiva de sujeito é elaborada a partir do conceito de forma-sujeito de Louis Althusser, o qual Pêcheux adota e desenvolve no interior de sua teoria. Segundo Althusser,

[...] 'os sujeitos agem em e sob determinações das formas de existência histórica das relações sociais’ (cf. Haroche 1992: 177). E é a ideologia que determina esse processo. A tese central de Althusser é a de que a ideologia interpela os indivíduos em sujeitos; a ideologia e a própria possibilidade de ser sujeito são, para ele, uma só e mesma coisa (cf. Pêcheux 1988, Haroche 1992). (RODRÍGUEZ, 2000, p. 196).

O que a teoria formulada por Pêcheux faz é desenvolver nessa reflexão althusseriana sobre a interpelação do indivíduo em sujeito o papel da linguagem, que fora enunciado por Althusser. Sendo assim, uma afirmação fundamental para quem trabalha com a análise de discurso é a de que "a ideologia interpela o indivíduo em sujeito e este submetese à língua significando e significando-se pelo simbólico na história" (ORLANDI, 1999, p. 11). Se a tese central de Althusser é a de que a ideologia e a própria possibilidade de ser sujeito são a mesma coisa, para Pêcheux, essa estruturação em circunstâncias sócio históricas particulares repousa sobre a possibilidade de mecanismos linguísticos específicos.

A explicação da subjetividade não pode ser reduzida estritamente a tais mecanismos linguísticos, é claro, mas a delimitação e compreensão desses mecanismos são, sim, fundamentais para que se possa compreender o processo de constituição dos sujeitos. "O processo de constituição dos sujeitos coincide com o da constituição dos sentidos, e é esse processo que determina o funcionamento da linguagem" (RODRÍGUEZ, 2000, p. 197). 
É, portanto, ao inscrever-se na língua que o indivíduo é interpelado em sujeito pela ideologia, resultando uma forma-sujeito histórica, o sujeito jurídico, ou sujeito de direito, que caracteriza o sujeito do capitalismo. Trata-se de um sujeito ao mesmo tempo livre e submisso, um sujeito "capaz de uma liberdade sem limites e uma submissão sem falhas: pode tudo dizer, contanto que se submeta à língua para sabê-la" (ORLANDI, 2010, p. 50). Essa é a base do que se convencionou denominar na $\mathrm{AD}$, a partir de Althusser, de assujeitamento.

A noção de assujeitamento constitui importante crítica às duas formas de evidência que estão na figura da interpelação: a da constituição do sujeito e a do sentido. Isso quer dizer que a filosofia idealista da linguagem - que se apresenta sob o modo do objetivismo abstrato (a língua como sistema neutro, abstrato) ou do subjetivismo idealista (o sujeito como centro e causa de si) - é criticada pela teoria materialista do discurso, para a qual os sentidos não preexistem à língua, mas são constituídos nela e por ela. Do mesmo modo, para esta teoria o sujeito não é origem de seu dizer, não é senhor de seu discurso. $\mathrm{O}$ sentido, para a $\mathrm{AD}$, não existe em si mas é determinado pelas posições ideológicas colocadas em jogo no processo sócio histórico em que as palavras são produzidas (cf. ORLANDI, 2010, p. 42).

As evidências do sentido e do sujeito são, na realidade, um efeito ideológico. Elas não nos deixam perceber o caráter material dos sentidos, isto é, a historicidade de sua construção. A evidência do sentido e a evidência do sujeito vêm, portanto, de um apagamento: o da interpelação. Trata-se de um apagamento que gera uma ilusão subjetiva a qual coloca-nos como origem da linguagem.

\section{REFERÊNCIAS BIBLIOGRÁFICAS}

BARBOSA FILHO, Fábio Ramos. A escrita urbana nos (des)limites do (im)possível/Fábio Ramos Barbosa Filho. Campinas, SP: [s.n.], 2012. FERREIRA, Maria Cristina Leandro. Linguagem, Ideologia e Psicanálise. Estudos da Lingua(gem). Vitória da Conquista, n.1, p. 69-75, junho/2005.

FERREIRA, Maria Cristina Leandro; INDURSKY, Freda (Org.); MITTMANN, Solange (Org.). Memória e história na/da análise do discurso. 01. ed. campinas: Mercado de Letras, 2011. v. 01. 335p.

Análise do Discurso e suas interfaces: o lugar do sujeito na trama do discurso. Organon (UFRGS), v. 24, p. 17-34, 2010.

MARIANI, Bethania S. C. Subjetividade e imaginário linguístico (impresso). Linguagem em (Dis)curso, Tubarão - Ed. Da UNISUL, v.3, p. 55-72, 2003. 
ORLANDI, Eni. Exterioridade e ideologia. Cadernos de Estudos Linguísticos (UNICAMP), Campinas, v. 30, p. 27-34, 1996.

Do sujeito na história e no simbólico. Escritos, Campinas, n.4, p. 17-22, 1999.

A análise de discurso e seus entremeios. Cadernos de Estudos Linguísticos (UNICAMP), n. 42, p 21-41, 2002.

Análise de Discurso: princípios e procedimentos. $9^{\mathrm{a}}$ ed. Campinas, SP: Pontes Editores, 2010.

Interpretação, autoria, leitura e efeitos do trabalho do simbólico. $6^{\mathrm{a}}$ ed. Campinas, SP: Pontes Editores, 2012.

PÊCHEUX, Michel. Semântica e Discurso: uma crítica à afirmação do óbvio. $4^{\mathrm{a}}$ ed. Campinas, SP: Editora da UNICAMP, 2009.

O Estranho Espelho da Análise do Discurso. In: COURTINE, Jean-Jacques. Análise do Discurso político: o discurso comunista endereçado aos cristãos. São Carlos, SP: EdUFSCAR, 2009.

RODRÍGUEZ-ALCALÁ, Carolina. Língua, Nação e nacionalismo: um estudo sobre o guarani no Paraguai. Carolina Maria Rodríguez Zucolillo. Campinas, SP: [s.n.], 2000.

Em torno de 'Observações para uma Teoria Geral das Ideologias', de Thomas Herbert. Estudos da Lingua(gem), Vitória da Conquista, v. 1, p. 15-21, 2005.

SARGENTINI, Vanice Maria Oliveira; BARONAS, Roberto Leiser. O curso de Linguística Geral: apontamentos de uma leitura da Análise do Discurso. Revista do GEL (Araraquara), v. 1, p. 30-38, 2007.

*Mestre em Linguística pela Universidade Federal da Grande Dourados (UFGD), Professora de língua portuguesa e língua inglesa do Instituto Federal de Mato Grosso do Sul (IFMS), Doutoranda em Linguística pelo Instituto de Estudos da Linguagem (IEL), na Universidade Estadual de Campinas (UNICAMP). Email: bicavichia@gmail.com. 